University of Nebraska - Lincoln

DigitalCommons@University of Nebraska - Lincoln

$1-19-2003$

\title{
Strategies for Providing Access to a Specialized Collection: Cataloging Decisions Affecting the Quilt Newsletter Collection at the University of Nebraska-Lincoln
}

Charity K. Martin

University of Nebraska-Lincoln, charity.martin@library.tamu.edu

Mary Cassner

University of Nebraska - Lincoln, mcassner1@unl.edu

Follow this and additional works at: https://digitalcommons.unl.edu/libraryscience

Part of the Library and Information Science Commons

Martin, Charity K. and Cassner, Mary, "Strategies for Providing Access to a Specialized Collection: Cataloging Decisions Affecting the Quilt Newsletter Collection at the University of Nebraska-Lincoln" (2003). Faculty Publications, UNL Libraries. 68.

https://digitalcommons.unl.edu/libraryscience/68

This Article is brought to you for free and open access by the Libraries at University of Nebraska-Lincoln at DigitalCommons@University of Nebraska - Lincoln. It has been accepted for inclusion in Faculty Publications, UNL Libraries by an authorized administrator of DigitalCommons@University of Nebraska - Lincoln. 


\title{
Strategies for Providing Access to a Specialized Collection: Cataloging Decisions Affecting the Quilt Newsletter Collection at the University of Nebraska-Lincoln
}

\author{
Charity K. Martin \\ Mary Cassner
}

\begin{abstract}
Libraries often receive gifts of unique, specialized materials to add to their collections. In 1999, the University Libraries at the University of Nebraska-Lincoln received a quilt newsletter collection as an addition to the American Quilt Study Groups quilt collection. In order to provide the best access to the collection, the cataloger in charge of the quilt newsletters developed a unique classification number for the collection and organized the collection by state of origin, followed by organization. [Article copies available for a fee from The Haworth Document Delivery Service: 1-800-HAWORTH. E-mail address: <docdelivery@haworthpress.com> Website: <http://www.HaworthPress.com> () 2003 by The Haworth Press, Inc. All rights reserved.]
\end{abstract}

KEYWORDS. Specialized collections, unique classification numbers, quilts, access, cutter numbers

At times, libraries develop comprehensive collections on unusual subjects. In order to maximize access to these specialized collections, librarians must

Charity K. Martin, MA, MLS, is Cataloger, University of Nebraska-Lincoln, 322 Love Library, P.O. Box 884100, Lincoln, NE 68588-4100. Mary Cassner, MEd, MLS, is Subject Specialist Librarian, University of Nebraska-Lincoln, 203 C. Y. Thompson Library, Lincoln, NE 68583-0717.

Cataloging \& Classification Quarterly, Vol. 36(1) 2003 http://www.haworthpress.com/store/product.asp?sku=J104

(C) 2003 by The Haworth Press, Inc. All rights reserved. 
sometimes make certain cataloging decisions. For example, libraries may class these materials together so that they remain as a physical unit within the larger collection. Libraries utilizing Library of Congress (LC) classification can encounter problems when assigning call numbers, since LC classification does not always provide for a broad range of classification numbers to accommodate the materials. ${ }^{1,2}$

In 1999, the University of Nebraska-Lincoln (UNL) Libraries received such a collection. During that year, the American Quilt Study Group (AQSG) moved its headquarters from San Francisco to the UNL campus. The AQSG is an international organization whose mission is to support, present, and preserve research on quilts, quilt making, and quilt makers. As part of UNL's arrangement with AQSG, the University Libraries agreed to incorporate the AQSG materials into its collections, by cataloging, housing, and preserving these materials. This enables AQSG members, UNL faculty and students, and the general public access to one of the largest research collections of quilt and quilt making documentation in the United States. Within the collection are 231 newsletter titles produced by quilt guilds from across the United States, Canada, and Great Britain. This smaller collection is unique in itself, and the cataloger responsible for the quilt serials realized it needed specialized treatment.

\section{IMPORTANCE OF THE COLLECTION}

In 1995, Diane Crispell reported that about 15.5 million Americans enjoy quilting. ${ }^{3}$ Quilt practitioners disseminate information about their craft in a variety of ways, the most common method being quilt-related books and journals. At the community level, quilt auxiliaries or guilds are common and they publish newsletters to further communication among their registered members. The newsletters may consist of a few sheets of paper, photocopied information sheets, or attractively developed bulletins. The AQSG newsletter collection includes all of these types of materials. Many of the titles received are ceased or inactive, while others are still being published. These newsletters are an important record of the grassroots quilting culture within local communities. Each organization's newsletter is unique, having a different tone, and containing different elements of quilting. Some are formal in nature, while others are very informal. A sampling of the newsletter content found social news of the group's members, quilt patterns, recipes, announcements of meetings, notices of upcoming quilt exhibits or new books, and continuing education opportunities. As a local record of this national activity, these newsletters are extremely valuable. 


\section{ACCESSIBILITY ISSUES}

In order to organize the materials to optimize accessibility, several issues were considered. The first question concerned who would use this collection. The quilt newsletters are part of the greater American Quilt Study Group Research Library and quilt practitioners, especially AQSG members, would be heavy users. According to the public services librarian responsible for the quilt collection, other users include students and faculty in the fiber arts and textile fields. Historians and popular culture scholars also potentially have interest in the quilt newsletters, because the newsletters chronicle the grass roots nature of this American folk art. The second question concerned how patrons would look for the quilt newsletters. This would vary according to the user. Upon reflection and consultation with colleagues, the cataloger concluded that most patrons look for the newsletters either by organization name or by location, with perhaps more emphasis on the state in which an organization was located.

The third question concerned how to house the quilt newsletters. In accordance with the agreement with AQSG, all quilt materials are integrated into UNL's overall collection. The final question and most important question considered concerned whether or not the quilt newsletters should be shelved with the rest of the AQSG research library collection or as a separate collection. The newsletters differed from the other quilt materials in that they dealt with guilds and associations of quilters as opposed to quilting itself. If the newsletters were shelved with other quilt materials, the uniqueness of the collection would be muted, perhaps even lost, within the greater quilt collection. Also, placing the quilt newsletters within the larger collection would result in very long, unwieldy call numbers. The newsletters emphasize quilt organizations, serving as more than just a source of quilting information, and should be recognized as such.

\section{PHYSICAL ORGANIZATION}

The lack of physical organization of the newsletters resulted in significant problems for the cataloger responsible for the project. The newsletters were not in chronological order, making it difficult to locate the first issue of a title and determine if any title changes had occurred. This required the cataloger to examine each box in order to determine the cataloging issues for a specific title, a time-consuming process.

After consulting with a fellow serials cataloger, the cataloger in charge of organizing the newsletters determined that physically arranging the newsletters by the state of publication followed by quilting organization provided the best method of facilitating the cataloging. The cataloger then could easily note 
any connections between titles and/or organizations. The newsletters of the organizations, including title changes, would then be put in chronological order. A cataloging paraprofesssional with a strong interest in quilting volunteered to organize the entire newsletter collection. She spent several hours a week for two months arranging the newsletters according to the cataloger's specifications.

The cataloger then examined the newsletter titles. Flyers and supplements were pulled from the collection and labeled by the associated quilt guild, which included items such as registration forms for various guild workshops, guild by-laws, and memberships directories. Given the time-dated nature of the registration forms and the supplementary nature of the by-laws and directors, these items were put aside for the collection development librarian's consideration. If approved, they will be cataloged and included in the quilt newsletter collection as separate pieces or possibly as part of a collection level record. At present, a decision has not been made.

\section{CLASSIFICATION AND CALL NUMBER}

Unique collections often comprise various and numerous materials devoted to the subject of particular interest. In many cases, LC classification does not have enough depth to classify all of the materials ${ }^{4,5}$ and it is sometimes necessary for a library to customize the LC Classification in order to provide greater flexibility and better meet the needs of its users. Suggestions made by other libraries for the differing classification include African languages, ${ }^{6}$ veterinary science, ${ }^{7}$ genealogical materials, ${ }^{8}$ and computer science. ${ }^{9}$

In preparing to catalog the quilt newsletters, one of the most important decisions was the selection of the classification number. The LC classification for quilts, quilting and quilt makers is TT835. In September 2002 over 1,300 items, both serial and monograph, had this classification number. Because of UNL's extensive collection in this area, this classification number is extremely crowded. Cutter numbers have become very long in an effort to fit everything into this classification as a result of the agreement to incorporate all quilt materials into the larger UNL collection. Concern about accessibility of the newsletter collection within the larger quilt collection and a desire to keep the newsletters physically close to one another led the cataloger to consider how best to provide access to the collection. Given that the quilt newsletters are so similar in focus, that cataloger decided to give the newsletters a special classification number of TT830, an unused LC classification number under the Home Arts. This number comes between Knitting (TT810-829) and Locker Hooking (TT833), also known as latch hook. Quilting and Patchwork (TT835) 
comes immediately after locker hooking. UNL has no items under TT833 and an unused classification number provides necessary room for the collection to grow. Another consideration dealt with the subject focus of the collection, quilt guilds and associations. The cataloger decided to place these items before the general quilt collections. In order to meet these needs, the classification of TT830 was chosen, to be cuttered by state and then by organization.

Choosing TT830 as a classification number for quilting organizations does have disadvantages. If UNL should acquire a collection of latch hooking materials, the cataloger would have to choose whether to keep the LC classification of TT833 or reassign that area to a different locally determined classification. If the classification was kept, then the quilt newsletter collections would be separate from the general quilt materials found in TT835. If, at sometime in the future, LC were to assign other subjects to the classifications of TT830 to TT834, the cataloger would have to decide whether to utilize the LC classification scheme or further adapt the local practice.

The cataloger could have chosen to use the classification of TT834 instead, thus bypassing the problem caused by maintaining latch hooking as TT833. Utilizing TT834 would serve to class the newsletters of the organizations before the general quilting materials and was seriously considered by the cataloger. Upon consultation with the principal serials cataloger, the cataloger concluded that, because of the large number of quilt items already cataloged with more materials arriving, reserving the classifications of TT830 to TT835 for the entirety of the quilt collection would accommodate the growth. Another solution considered would have been to utilize instruction sheet F220 of the $\mathrm{Li}$ brary of Congress Subject Cataloging Manual: Classification, ${ }^{10}$ which suggests utilizing '.A1-Z' as a cutter. Due to the already copious amounts of material classed in TT835, this idea was rejected.

It may be asked why the cataloger chose to cutter first by state and then by organization. Other ways considered included to cutter by town, then by organization, or by organization alone, or perhaps by organization, then town. Cuttering by state allows all newsletters from a given state to be gathered in a sub-collection. Both the cataloger and the public services librarian responsible for the subject area concluded that patrons would search for the newsletters in this manner. The decision to use a second cutter by organization was based on the geographical area covered by the quilt organization and the expected patron usage of the collection. The areas covered by the various quilt guilds vary in size, with some only representing a specific town while others cover regions involving numerous towns and local guilds within a state. Also, the public services librarian believed that patrons were more likely to look for a specific organization within a state, than to look for a specific town within a state. 
One problematic issue centered on the assignment of cutter numbers to organizations that change their name. The solution hanged upon whether or not the title proper changed when the organization name changed. If the title stayed the same while the organization name changed, the cutter number would remain constant. However, if both the organization name and title changed, the work was considered a new entity and a new call number assigned based on the most recent organizational name. Older issues would retain the original call number.

\section{BIBLIOGRAPHIC ORGANIZATION}

Before commencing to catalog the newsletters, the basic bibliographic record for the newsletters was developed to ensure consistency within the newsletter section of the quilt collection. The decision to use the issuing organization as the main entry was made because the newsletters primarily cover the activities of the guild publishing them. The quilt guilds are usually confined to a specific U.S. state, such as California, so a 043 (geographic area code) was required. A 610 field (corporate author subject heading) for the organization and two 650 fields (topical subject heading) were included. The first 650 field, "quilt makers," would have a subfield $\mathrm{z}$ for the state and another for the town if the guild were restricted to a specific town. The second 650 field was "Quilting-Periodicals." In accordance with the agreement made with the American Quilt Study Group, a 793 field (local uniform title) was added for the American Quilt Study Groups Research Library.

With these decisions in place, the actual cataloging began. The cataloger thoroughly examined the run of each newsletter title. Title changes, variations in organizational name, and chronological and numbering irregularities were noted for inclusion in the bibliographic record. Numbering and date errors were found in the majority of the newsletter titles. A general note, usually a 515 (numbering peculiarities note), was often added to the record to explain the various errors, such as "numbering very irregular" and "many issues lack date." Examples of more specific notes explaining a numbering error are "Issues for Apr.-June 1998 lack dates," or "Issues for April and May 1998 both called vol. 5, no. 4."

In checking the OCLC (Online Computer Library Center) database, no bibliographic copy for the quilt newsletters was found. This is not surprising. During the initial cataloging of the AQSG collection, the percentage of quilt periodicals (chiefly magazines or journals) with copy was smaller than the norm for serials in other subject areas. Given the popular nature of quilting, the catalogers of the initial quilt collection had anticipated that approximately 80 
to 90 percent of the quilt periodicals would have copy. Instead, only 50 to 60 percent had bibliographic copy in OCLC. The reason remains unclear. One possible explanation is that because of the 'popular' nature of quilting, public libraries rather than academic libraries are more likely to have quilting as a collection focus. Public libraries catalog their serials less often, therefore less copy for quilting periodicals would be found in OCLC. Given that quilt newsletters are local publications meant primarily for guild members, libraries might not receive issues. If they do, the issues are probably considered ephemeral and not cataloged. In any event, the lack of OCLC bibliographic copy meant that every quilt newsletter title required original cataloging by a professional librarian.

Utilizing an OCLC constant data record set up with the MARC fields considered necessary, each title was cataloged following AACR2r with separate records for title changes in accordance with successive entry principles. Although a paraprofessional could have assisted in the cataloging, the variations in numbering, chronology, and titles found within a sampling of the newsletters convinced the cataloger that each title required close attention to the issues in order for a complete, accurate bibliographic record to be created.

The cataloger checked the OCLC authority file to determine if establishing the corporate name of the various quilt organizations was necessary. The authority file revealed that, like the titles themselves, very few of the quilt organizations had authority records. When necessary, the heading for the organization was established and added to the OCLC authority file via NACO (Name Authority Cooperative) procedures. For some organizations no cross-references were needed; however, often the quilt guild would refer to itself by its initials. Variants of the name beyond the use of initials were seldom found.

\section{INCIDENTAL FACTS}

During the cataloging process, many incidental facts concerning the American quilting subculture were revealed. There were 231 quilt newsletter titles cataloged, not including title changes. All states were represented except for Wyoming and Hawaii. California had the most titles. The only foreign newsletters came from Canada and England. Only $21 \%$ of the titles are being currently received by the AQSG. Thirty percent of the newsletters had one or more title changes. Although not germane to the cataloging of the newsletters themselves, these facts do reveal interesting information. 


\section{PROCESSING}

After cataloging was complete, processing of the issues began. If the quilt newsletter title was still active, i.e., being received, a check-in record was created for the current issues. These current issues were then sent to the current periodicals section of the C.Y. Thompson Library, where the circulating quilt materials are housed. The older issues were divided into binding units and shipped to a commercial bindery.

The newsletters created problems for the binding section because each title required action on a case-by-case basis. The publishers of the newsletters are seldom concerned with consistent numbering or frequency, so determining if issues were missing was difficult. Variations in size also made binding difficult. Another bothersome characteristic was the lack of margins on the pieces, resulting in a possible loss of information during the binding process. Finally, there was the issue of pocket materials that came with issues, such as material swatches or folded patterns.

If any issues of a title were lacking, the units were given in-house temporary binding. This way, if the missing issues of a title are ever acquired, the unbinding and rebinding will not result in the loss of text. If all issues were available, the binding units were sent to a commercial binder for permanent binding. Whether temporarily or permanently bound, the issues were then sent to C. Y. Thompson Library's circulating collection.

\section{CONCLUSION}

Quilting is one of the great American grassroots art forms, but the need to document it is often overlooked. The quilt newsletter collection provides a record of the quilting phenomena at the local level. Because quilting has not been a subject of intense academic research, LC classification does not provide enough room to convey the depth or range of the popular literature. Thus, in order to provide the best possible access to the newsletter collection, it was deemed necessary to create a new classification number for the newsletters and their organizations and to ensure that the bibliographic records were consistent in their format. This will enable all researchers, the academic researcher and the quilt enthusiast, to access a fascinating aspect of the American quilting subculture.

Received: June 2002 Revised: September 2002 Accepted: October 2002 


\section{BIOGRAPHICAL NOTES}

1. William E. Studwell, "What's the Number? An Unofficial and Unabashed Guide to the Library of Congress Classification for the Social Sciences," Behavioral \& Social Sciences Librarian 13, no. 1 (1994): 39-48.

2. Jeffrey C. Huestis, "Clustering LC Classification Numbers in an Online Catalog for Improved Browsability," Information Technology and Libraries 7 (Dec. 1988): 381-393.

3. Diane Crispell, “Quilting Isn't Quitting," American Demographics 17, no. 4(1995): 14-16.

4. Studwell, "What's the Number?"

5. Huestis, "Clustering LC Classification Numbers."

6. M. R. Aderibigebe and D. J. E. Udoh. "L.C. Subclass PL8000-8844: A Case for Revision," Cataloging \& Classification Quarterly 10, no. 3 (1990): 77-90.

7. Nancy L. Pelzer, "Veterinary Subject Headings and Classification: a Critical Analysis," Cataloging \& Classification Quarterly 18, no. 2(1993): 3-18.

8. Shiu Y. Mak, "Cataloging Genealogical Materials," Kentucky Libraries 65, no. 3 (summer 2001): 34-36.

9. Jian-zhong (Joe) Zhou, "A New Subclass for Library of Congress Classification, QF: Computer Science," Cataloging \& Classification Quarterly 26, no. 1 (1998): 37-44.

10. Library of Congress, Office for Subject Cataloging Policy. Subject Cataloging Manual: Classification. 1st edition. Washington, D.C.: Cataloging Distribution Service, Library of Congress, 1992. 